\title{
The Transformer Condition Estimation Method Research
}

\author{
Junyu Dong ${ }^{1, a}$, Jie Wei ${ }^{1, b}$, Hong Yu ${ }^{1, c}$, Zhigang Cui ${ }^{1, d}$, Yongqin Chen ${ }^{1, e}$, Xin \\ Chen $^{1, \mathrm{f}}$, Ma Lan $^{1, \mathrm{~g}}$ \\ ${ }^{1}$ Yunnan Power Grid Corporation, Kunming, China \\ aemail: 1262842966@qq.com, bemail:HDliyaning@163.com, cemail:894333697@qq.com
}

\begin{abstract}
Keywords: Running status, Evaluation, Power grid equipment
Abstract: For the electrical transformer equipment state analysis to obtain the accurate status, and reliable maintenance strategy, to long-term safe, reliable and economic operation of the power grid is particularly important. So, it is proposed the condition evaluation method of the power transformer equipment, which is based on the defect, testing, operation and so on information. And equipment status evaluation rules, basic data, the evaluation results are consistent data information extraction, identification rule, the equipment specification for intelligent evaluation model are researched and established. In this paper, it is proposed to optimize the maintenance plan for power transformer equipment in the service life of period, guarantee the safety and reliability of the, improve its operation safety and reliability.
\end{abstract}

\section{Introduction}

Power transformer is the essential and costly equipment in the power system. Its fault diagnosis is always widely regarded at home and abroad. Incipient fault of transformer is detected as early as possible, which can make for reducing the loss by the interruptions of temporary ceasing run and increasing the level of the run and maintenance ${ }^{[1-3]}$.

In order to ensure safe and reliable operation of power equipment, and power sector need to regularly every year to the preventive test electrical equipment power outage, according to the test results for repair. In inspection of power transmission and transformation equipment running status at present is mainly through a power outage test its mechanical properties and the insulation condition, with operating personnel not timely grasp the situation of power transmission and transformation equipment operation, resulting in the preventive maintenance cycle is also often have accidents. According to statistics, $10 \%$ of the power transmission and transformation equipment failures are caused by improper maintenance, overhaul complete disintegration of power transmission and transformation equipment, time, cost is high, and the dissolution and reassemble will cause a lot of defects, the resulting accident examples are too numerous to list.

For power transformer equipment status analysis to obtain the status of accurate, and reliable maintenance strategy, to long-term safe, reliable and economic operation of the power grid is particularly important, mainly reflected in, 1) to optimize the maintenance plan for power transmission and transformation equipment in the period of service life of the safety and reliability of guaranteed, to improve the operation safety and reliability, 2) can provide safe and reliable operation of the power transmission and transformation equipment strategy of reducing unplanned production loss and optimize the maintenance plan to provide an effective long-term planning tool, 3) the optimization of power transmission and transformation equipment all, reliability and efficiency of transformer substation contribution ability, provide a basis for planning, financial management plan and prolong life.

Nowadays diversified artificial intelligence technology is combined with DGA, such as BP, Bayesian network, particle swarm optimization (PSO) and so on ${ }^{[4-6]}$. However, these approaches have flaws in the diagnosis ability, diagnosis velocity. SVM has global optimization and well generalization ability.

Experimental results show that the proposed algorithm in this paper improves the preciseness judgment rate of transformer fault diagnosis. Thus, the proposed method is an effective and robust. 


\section{The intelligent condition evaluation method for the power transmission equipment}

In this paper, it is proposed the power transmission and transformation equipment condition evaluation method based on fault tree state evaluation, and according to this method development power transmission and transformation equipment state overhaul auxiliary decision support system. The evaluation method according to the amount of equipment state degree of impact on the health status of the equipment, since the childhood is divided into 1, 2, 3, 4 four weight level, corresponding to different weight coefficient. According to the state of degradation is serious, from light to heavy into I, II, III and IV level 4, evaluations of the different values ${ }^{[7-9]}$.

Through comprehensive analysis of the state, comprehensive evaluation of equipment state (normal, attention, abnormalities and severe, four state), normal state can run normally, attention state should strengthen the operation monitoring, abnormal state should be arranged timely maintenance, severe state should arrange inspection as soon as possible. Device status measure right attaches great importance to the state of the influence degree of the safe operation of equipment, from light to heavy is divided into four levels, the weight of corresponding weights respectively weight 1 , weight 2 , weight 3 , weight 4 , its coefficient is $1,2,3$, 4.Weight 1,2 and general state of corresponding weights, weight 3 and 4 are corresponding with the important status. State the amount of degradation is depending on the state of degradation from light to heavy is divided into four classes, respectively I, II, III and IV level. Its corresponding basic score is 2, 4, 8, 10 points. Button state quantity score is determined by the state the amount of degradation and weight, the quantity of state should deduct your score is equal to the quantity of state firm points value multiplied by weight coefficient, which is seen in the Table 1. Not to evaluate a certain quantity of state, no penalty. The following transformer is used for the example. Evaluation of transformer components should be taken into account at the same time points and parts of single state variable total points, unit status evaluation standard are shown in Table 1. When any state points and components combined single points of normal state stipulated in Table 1 at the same time, as a normal state. When any individual points or parts all state amount total points at the same time the attention of the state stipulated in Table 1, as a note. When any amount of individual points of abnormal or severe state stipulated in Table 1, it is the abnormal or severe state.

Table 1. Corresponding to transformer unit status and evaluation points

\begin{tabular}{|c|c|c|c|c|c|c|c|}
\hline \multirow{2}{*}{$\begin{array}{c}\text { Condition } \\
\text { Parts }\end{array}$} & \multicolumn{3}{|c|}{ Normal State } & \multicolumn{2}{c|}{ Attention State } & $\begin{array}{c}\text { Abnorma } \\
\text { 1 State }\end{array}$ & $\begin{array}{c}\text { Serve } \\
\text { State }\end{array}$ \\
\cline { 2 - 8 } & Total & Single & Total & Single & Single & & Single \\
\hline General & $\leq 30$ & $<10$ & $>30$ & $12 \sim 20$ & 24 & & $\geq 30$ \\
\hline Ontology & $\leq 30$ & $<10$ & $>30$ & $12 \sim 20$ & 24 & & $\geq 30$ \\
\hline Casing & $\leq 30$ & $<10$ & $\geq 30$ & $12 \sim 16$ & 24 & & $\geq 30$ \\
\hline $\begin{array}{c}\text { Non-electricity } \\
\text { protection } \\
\text { system }\end{array}$ & $<30$ & $<10$ & $\geq 30$ & $12 \sim 16$ & 24 & & $\geq 30$ \\
\hline
\end{tabular}

When all the parts as is normal state, the overall evaluation is normal state. When any parts status to pay attention to the state, abnormal status, or serve state, the overall evaluation should the one of the most serious condition. The overall evaluation of overall is divided into parts total points. 


\section{The typical default tree model of the transformer}

In this paper, it is proposed method of the intelligent condition evaluation for the power transmission equipment. The very important part is the typical default tree of the power equipment. The typical default tree of the transformer has the general fault, ontology default, casing pipe default and non-electricity protection system default. Each kind of fault has subdivided the maintainable components of equipment.

\section{The support vector machine}

The course of the fault diagnosis is may looked as the course of pattern class [7]. SVM is a new machine study classification algorithm, which is proposed by Vapnik based on the VC dimensions theory of the statistical learning and the minimum principle of the structural risk [8]. The means is superiority to the BP network, especially is the studying for the small samples. Thus, it can get the better extension ability.

Its main thinking finds the biggest classification hyperplane in the linear separable condition. Supposing the samples $\left(x_{i}, y_{i}\right)_{i=1,2, \cdots, n}$ and $y_{i} \in\{-1,+1\}$ is output sort, $\mathrm{n}$ is the number of the training samples, $\mathrm{d}$ is the dimension of input vector. $x_{i} \in R^{d}$ is the $\mathrm{n}$ dimension input vector that is firstly mapped in a high dimension feature space. Then, SVM is used to process in high feature space. So, two types of classification problems may be denoted as

$$
y_{i}\left(\omega \cdot x_{i}+b\right)-1 \geq 0 \quad i=1,2, \cdots, n
$$

Where, $\mathrm{w}$ is the weight vector, $\mathrm{b}$ is deviation. The distance between $\mathrm{yi}=1$ and $\mathrm{yi}=-1$ is classification interval. Basic SVM theory is shown in the Fig.1.

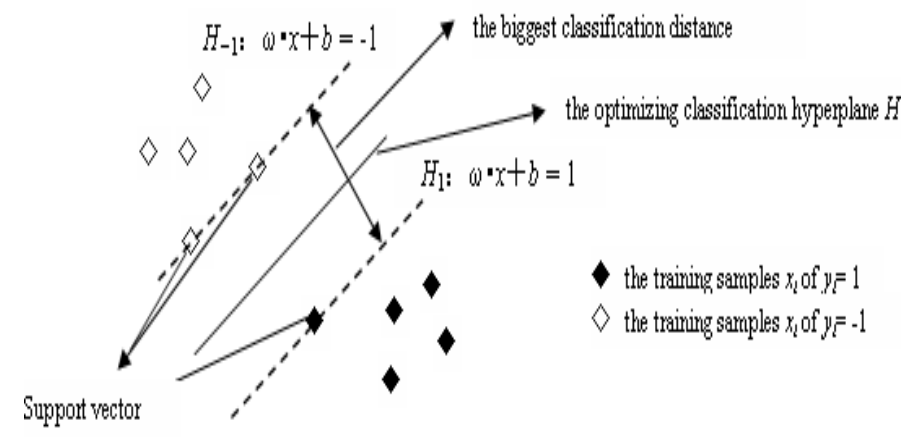

Figure1. Diagram of SVM theory.

In addition, considering possible existing some samples cannot be correctly plotted by the classification hyperplane. Thus, the non-negative relaxation factor $\varepsilon_{i}, i=1,2, \ldots, n$ is introduced. Then, the constraint condition of the SVM is changed as

$$
y_{i}\left(w \cdot x_{i}+b\right)-1+\varepsilon_{i} \geq 0, \quad i=1,2, \ldots, n
$$

In the nonlinear instance, the samples $\left(x_{i}, y_{i}\right)_{i=1,2, \cdots, n}$ are changed by the nonlinear change transition $\varphi(\cdot)$.

$$
\begin{aligned}
& \min \|\omega\|^{2} / 2+C\left(\sum_{i=1}^{n} \varepsilon_{i}\right) \\
& \text { s.t. } y_{i}\left(w \varphi\left(x_{i}\right)+b\right)-1+\varepsilon_{i} \geq 0
\end{aligned}
$$


Where, $C>0$ is the regularization constant that determine the balance of the experiential risk and complexity. By the Lagrange function, the inner product $\varphi\left(x_{i}\right) \cdot \varphi\left(x_{j}\right)$ of the feature space is replaced the kernel function, utilizing (2) and (3) of optimization problem is translated as [9]

$$
\begin{array}{ll}
\max _{\alpha} & \sum_{i=1}^{n} \alpha_{i}-\frac{1}{2} \sum_{i, j=1}^{n} \alpha_{i} \alpha_{j} y_{i} y_{j} \varphi\left(x_{i}\right) \cdot \varphi\left(x_{j}\right) \\
\text { s.t. } & \sum_{i=1}^{n} \alpha_{i} y_{i}=0,0 \leq \alpha_{i} \leq C, i=1,2, \cdots, n
\end{array}
$$

By getting the solution of (4), the corresponding decision function $f(x)$ is shown as

$$
f(x)=\operatorname{sgn}\left(\sum_{i=1}^{n} \alpha_{i} y_{i} K\left(x, x_{i}\right)+b\right)
$$

Where, $\operatorname{sgn}(\mathrm{x})$ is the signal function, its results is +1 or $-1 . K\left(x, x_{i}\right)=\varphi^{T}(x) \varphi\left(x_{i}\right)$ is kernel function, $\mathrm{n}$ is the number of support vector.

Choosing different kernel function can constitute various SVM classifiers. Existed many kernel functions $^{[10]}$, in this paper, the radial basis kernel function is used as the kernel function of the SVM, which expression is

$$
K\left(x, x_{i}\right)=\exp \left(-\frac{\left\|x-x_{i}\right\|^{2}}{2 \sigma^{2}}\right)
$$

Where, the parameter $\sigma$ is the kernel width. Choosing $\mathrm{C}$ and $\sigma$ for the diagnosis rate of the SVM has great influence on the generalization.

\section{The Application Results for the Intelligent Evaluation Method}

Transformer based on overall evaluation grading components evaluation grading evaluation is the most serious of the state, the sum of the total points overall is divided into parts. According to the evaluation results of transformer, formulate different maintenance strategies. Normal state can run normally, pay attention to the state still can continue to run, but should strengthen the monitoring in operation, and abnormal state should be arranged timely maintenance, severe state should arrange inspection as soon as possible. This paper puts forward the method to evaluate a certain power supply bureau subordinate equipment, the evaluation results are shown in Table 2. 
Table2. The transformer evaluation results

\begin{tabular}{|c|c|c|c|c|c|c|}
\hline Transformer substation & \multicolumn{5}{|c|}{ Voltage Level(kV) } & $\begin{array}{c}\text { Points reasons and } \\
\text { Suggestions }\end{array}$ \\
\hline & 500 & 220 & 110 & 35 & 10 & \\
\hline $110 \mathrm{kV}$ chajie substation & & & $\begin{array}{c}\# 1 \\
\text { transformer }\end{array}$ & & & $\begin{array}{c}110 \mathrm{kV} 1 \# \text { main } \\
\text { transformer oil } \\
\text { surface } \\
\text { thermometer }\end{array}$ \\
\hline $\begin{array}{l}\text { 110kV huize } \\
\text { substation }\end{array}$ & & & $\begin{array}{c}\# 2 \\
\text { transformer }\end{array}$ & $\begin{array}{c}\# 1 \\
\text { transformer }\end{array}$ & $\begin{array}{c}\# 1 \\
\text { transformer }\end{array}$ & $\begin{array}{l}\text { \# } 2 \text { main } \\
\text { transformer: seal } \\
\text { aging serious, box } \\
\text { margin slightly oil } \\
\text { leakage, oil } \\
\text { conservator of } \\
\text { ontology oil level } \\
\text { is too low, } \\
\text { operation more } \\
\text { than } 10 \text { years. To } \\
\text { strengthen the } \\
\text { operation } \\
\text { monitoring. } \\
\text { Distribution } \\
\text { change \# } 1 \text { and \# } 1 \\
\text { stand in turn run } \\
\text { more than } 10 \\
\text { years. To } \\
\text { strengthen the } \\
\text { operation } \\
\text { monitoring }\end{array}$ \\
\hline $\begin{array}{l}220 \mathrm{kV} \text { fugong } \\
\text { substation }\end{array}$ & & $\begin{array}{c}\# 1 \\
\text { transfor } \\
\text { mer }\end{array}$ & & & & $\begin{array}{c}220 \mathrm{kV} 1 \# 1,3,4 \\
\text { main transformer } \\
\text { cooler upper } \\
\text { connection pipe } \\
\text { valves }\end{array}$ \\
\hline $\begin{array}{c}35 \mathrm{kV} \\
\text { Dongshan substation }\end{array}$ & & & & $\begin{array}{l}\# 1 \text { and } \# 2 \\
\text { transformer }\end{array}$ & & $\begin{array}{l}\text { Run for more than } \\
\text { a decade, \# } 2 \text { main } \\
\text { transformer fan } \\
\text { motor damage } 7 . \\
\text { To strengthen the } \\
\text { operation } \\
\text { monitoring and } \\
\text { replace the fan } \\
\text { motor as soon as } \\
\text { possible }\end{array}$ \\
\hline
\end{tabular}

\section{Conclusions}

With the development of social and economic dependence on power enhancement in all walks of life, the requirement of power system, power supply reliability is increasing day by day, there are different kinds of power system reliability is way, from the run can take on a variety of scheduling, switching, protection and control measures to strengthen the reliability of the existing system. From system planning can enhance the network architecture, namely, increasing the redundancy of equipment to provide continuous and reliable power supply. From the Angle of maintenance, shall promptly repair or update the status variation of power components, eliminate the safety hidden danger in power grid. Since entering the era of deregulation of the electric power industry, the power grid company on asset management level of demand is higher and higher, make full use of existing equipment, the implementation of reasonable maintenance strategy, can save a lot of fixed assets investment. In order to meet the requirements of building a resource-conserving and environment-friendly society, make 
full use of existing power assets, improve equipment reliability and prolong the service life of equipment, the power company to provide users with more economical, more reliably power has important significance.

In this paper, it is proposed method that it can embody the superiority of the SVM, which can get the better diagnosis results in the lesser samples, and improve the veracity and reliability for the transformer fault diagnosis.

State analysis to obtain the accurate state of power transmission and transformation equipment, and reliable maintenance strategy, to long-term safe, reliable and economic operation of the power grid is particularly important, mainly embodied in the power transmission and transformation equipment maintenance plan optimization in the period of service life of the safety and reliability of guaranteed, improve the operation safety and reliability. For safe and reliable operation of the power transmission and transformation equipment in the strategy to reduce unplanned production losses, optimization of maintenance scheme provides the effective long-term planning tools. Optimization of power transmission and transformation equipment all, reliability and efficiency of transformer substation contribution ability, provide a basis for planning, financial management plan and prolong life.

\section{References}

[1] Németh B, Laboncz S, Kiss I. (2009) Condition monitoring of power transformers using DGA and fuzzy logic. Electrical insulation conference, pp.373-376.

[2] Haitao Zhu, Xiaohua Liu, Ming Li, Haibo Li, Zhengting Wang, Yong Fang. (2010) Detection and diagnostic analysis of internal partial discharge in 750kV GIS disconnector. Journal of high voltage apparatus. 46(8): 6-9. In Chinese

[3] Min Chen, Koji Ulano, Youcheng Li, Astuhide Jinno. (2008) Application of combined PD sensor for GIS PD detection and condition monitoring. In proceedings of the international conference on condition monitoring and diagnosis.

[4] G. Henkelman, G.Johannesson and H. Jónsson, in: Theoretical Methods in Condencsed Phase Chemistry, edited by S.D. Schwartz, volume 5 of Progress in Theoretical Chemistry and Physics, chapter, 10, Kluwer Academic Publishers (2000).

[5] Barry Finlay, "Oil-filled electrical plant condition assessment interpretation of dissolved gas analysis," Internet Report, Advanced Technology Center, Pacific Power International, Newcastle, Australia, 1995.

[6] W. H. Tang, Z. Lu and Q. H. Wu, "A bayesian network approach to power system asset management for transformer dissolved gas analysis," DRPT, pp. 1460-1466, 2008.

[7] W. H. Tang, J. Y. Goulermas, Q. H. Wu and Z. J. Richardson, "A probabilistic classifier for transformer dissolved gas analysis with a particle swarm optimizer," IEEE Trans. on Power Delivery, vol. 23, no. 2, pp. 751-759, April 2008.

[8] S. Poyhonen, M. Negrea, A. Arkkio, et al, "Fault diagnostics of an electrical machine with multiple support vector classifiers," IEEE International Symposium on Intelligence Control, 2002.

[9] V. N. Vapnik, "The nature of statistical learn theory," Springer-Verlag, 1995.

[10] Jun Guan, Lizhong Xu, Aiye Shi, "Assessment method of water quality of monitoring data based on support vector machine," Application Research of Computers, vol. 23, no. 9, pp. 36-38, 2006.In Chinese 